\title{
Sleeve Gastrectomy and Gastroesophageal Reflux Disease
}

\author{
Naoki Hashimoto \\ Department of Emergency Medicine, Kindai University, Osaka, Japan \\ Email: gojigen000@gmail.com
}

How to cite this paper: Hashimoto, N. (2018)

Sleeve Gastrectomy and Gastroesophageal Reflux Disease. Open Access Library Journal, 5: e4987.

https://doi.org/10.4236/oalib.1104987

Received: October 15, 2018

Accepted: November 11, 2018

Published: November 14, 2018

Copyright (c) 2018 by author and Open Access Library Inc.

This work is licensed under the Creative Commons Attribution International License (CC BY 4.0).

http://creativecommons.org/licenses/by/4.0/

\begin{abstract}
Sleeve gastrectomy (SG) is occupied over $25 \%$ of bariatric procedures, which becomes the second most commonly performed bariatric procedure after RYGB. But incidence of gastroesophageal reflux disease (GERD) after SG was reported to be $6.5 \%-40 \%$. SG is regarded to induce or exacerbate GERD in general. Therefore preoperative manometry and GIF should be routinely performed. Patients with a lower esophageal sphincter (LES) or preexisting sever GERD should be taken into consideration during patients counseling and selection of the optimal bariatric procedure. Moreover, postoperative GIF should be performed to detect GERD, erosive esophagitis and Barrett's esophagus.
\end{abstract}

\section{Subject Areas}

Bariatric Surgery, GERD

\section{Keywords}

Bariatric Surgery, Sleeve Gastrectomy (SG), Gastroesophageal Reflux Disease (GERD)

\section{Introduction}

Sleeve gastrectomy (SG) is a vertical left gastrectomy of the body and fundus to create a long, narrow tubular gastric sleeve along the lesser curvature that reduces the size of gastric reservoir to $80-120 \mathrm{cc}$.

SG was developed in 1988 as the initial procedure in a staged approach to patients with morbid obesity [1].

However, the initial promising results of SG in terms of weight loss and resolution of comorbidities have rendered it popular not only as a first stage procedure but also a primary bariatric surgery. SG was described as an isolated pro- 
cedure in 1993 by Johnston et al. [2] with a minimally invasive alternative developed in 1999. SG is now considered as a newer stand-alone operation being performed with increasing frequency. In 2011, it occupied over 25\% of bariatric procedures worldwide, which became the second most commonly performed bariatric procedure after RYGB.

\section{Sleeve Gastrectomy and GERD}

The second international Consensus Summit for Sleeve Gastrectomy reported that the mean prevalence of postoperative GERD was $6.5 \%$ ranging from 0 to $83 \%$ [3].

Cottan et al. [4] reported a series of 126 patients who underwent SG and found a $20 \%$ incidence of GERD at 12 months postoperatively. Hamoui et al. [5] reported 131 SG patients with a $12.7 \%$ incidence of GERD at 13 months; Nocca et al. [6] reported 163 SG patients with an $11.8 \%$ incidence of GERD at 24 months; and Soricelli et al. [7] reported 264 SG patients with a $7.8 \%$ incidence of GERD at 24 months.

SG is regarded to induce or exacerbate GERD in general, although there is a debate regarding whether SG induces or treats GERD.

\subsection{Lower Esophageal Sphincter after Sleeve Gastrectomy}

In a recent review of the literature, an increase in reflux symptoms after SG was reported in four studies [8], while seven studies reported a reduction in GERD symptoms postoperatively [9].

Multiple anatomical or physiologic factors have been proposed and identified that could contribute to the worsening of reflux or the de novo development of GERD after SG. Several studies [10] [11] have suggested that the increased incidence of GERD in relation to SG may be due to a significant decrease in lower esophageal sphincter resting tone and pressure after surgery.

Decreasing in lower esophageal sphincter pressure (LESP) from disruption of phrenoesophageal ligament, partial resection of sling fibers could be the cause of GERD. The main function of the LES is to prevent the retrograde movement of gastric content into the esophagus. However, if the normal function of this sphincter is altered, such as prolonged lower esophageal sphincter relaxation, a hypotensive lower esophageal sphincter, or anatomic disruption of the gastroesophageal junction as a hiatal hernia, gastroesophageal reflux of different severity can occur.

The anatomy of LES has been carefully evaluated by Korn et al. [12] [13] showing the presence of 2 different fibers: "clasps" and "sling". The clasp fibers are located at the right portion of the sphincter and are the final prolongation of semicircular fibers. The sling fibers are located at the left site of the sphincter and are anchored at the antrum. In SG, gastric section should start $1-2 \mathrm{~cm}$ from the esophagogastric junction to avoid or to diminish the production of leak. If gastric section is done 3 or more $\mathrm{cm}$ from the EG junction, probably most sling 
fibers are divided, which may affect LES pressure and pathologic acid reflux may appear.

Therefore, I think manometry and $\mathrm{pH}$ metry should be performed as routine examination to make a diagnosis and assessment of GERD pre and postoperative.

Braghett's group [14] reported manometric changes occur in LES after SG. Mean LES resting pressure (LESRP) decreased significantly after SG from $14.2 \pm$ 5.8 to $10.5 \pm 6.06 \mathrm{~mm} \cdot \mathrm{Hg}(\mathrm{p}=0.01) .15 \%$ of patients presented normal LESRP $(23.1 \pm 3.7 \mathrm{~mm} \cdot \mathrm{Hg})$ and $85 \%$ were hypotensive, with a mean resting pressure of $8.3 \pm 2.6 \mathrm{~mm} \cdot \mathrm{Hg}$. GIF findings also are erosive esophagitis and cardia dilatation in these patients .Burgerhart [15] observed a decrease in LES resting pressure from $18.3 \pm 9.2$ to $11.0 \pm 7.0 \mathrm{~mm} \cdot \mathrm{Hg}(\mathrm{p}=0.02)$ measured by high resolution manometry. Tai et al. [16] demonstrated significant increases in GERD (47\%), erosive esophagitis (67\%), and hiatal hernia (27\%) after SG.

Klaus and Weiss [17] suggested that preoperative manometry should be routinely performed and that patients with a lower esophageal sphincter pressure should not undergo SG.

The narrow sleeve (high-intragastric pressure), smaller antrum and stricture of incisura angularis could be other causes.

The size and configuration of the gastric sleeve may also have a significant effect on the risk for postoperative GERD. An overly narrowed or strictured sleeve may result in reflux and decreased esophageal acid clearance [18]. Finally, the presence of a hiatal hernia that is not recognized or that develops over time may result in the development of significant reflux symptoms. The importance of these anatomical factors in determining the risk of GERD after SG is highlighted by several series that describe technical details of the procedure that can reduce the incidence of postoperative GERD. These details include attention to the sleeve size and volume, avoidance of narrowing the gastric body or pylorus, and identification and repair of all associated hiatal hernias [19]. One series demonstrated that attention to crural repair during SG resulted in GERD remission in $73 \%$ and a decrease in the development of de novo GERD from $23 \%$ to $0 \%$ [20]. These series suggest that technical modification may have a major role in reducing the risk of postoperative GERD with SG.

Most surgeons recommend the approximation of the crura if hiatal hernia is found during SG. Dissection to the posterior is necessary to inspect and repair the hiatal hernia.

\subsection{Case Reports of Esophageal Adenocarcinoma after SG}

Esophagogastric cancer after bariatric procedures was reported in less than 40 cases, and to our knowledge, only three cases of esophageal adenocarcinoma after SC have been published. Sheepers et al. [21] described the case of 57 years woman who was submitted for a SG and was diagnosed with esophageal adenocarcinoma four months after SG. Sohn et al. [22] 44 years woman who under- 
went SG developed an adenocarcinoma of the gastroesophageal junction 2.5 years after SG. Surprisingly, in both cases the SG was performed without previous endoscopic evaluation, making it impossible to rule out the presence of early or premalignant esophageal lesions. As a matter of fact, in the first case, the esophageal adenocarcinoma diagnosed four months after SG had been probably present at the time of SG. Wright et al. [23] reported that 48 years male with morbid obesity and normal preoperative endoscopy and esophagogram who underwent a laparoscopic SG and developed an esophageal adenocarcinoma after five years.

\section{Conclusions}

SG is an operation which may produce pathologic reflux of acid as well as reflux of duodenal content due to decrease LES and narrowed or strictured sleeve.

Therefore preoperative manometry and GIF should be routinely performed. Patients with a lower LES or preexisting sever GERD should be taken into consideration during patients counseling and selection of the optimal bariatric procedure. Moreover, postoperative GIF should be performed to detect GERD, erosive esophagitis and Barrett's esophagus.

Further study is clearly indicated to clarify the role of preoperative GERD in the selection of bariatric procedures, to evaluate the effect of SG on reflux potential and GERD, and to identify technical factors that may minimize the risks of persistent or de novo GERD after SG.

\section{Conflicts of Interest}

The author declares no conflicts of interest regarding the publication of this paper.

\section{References}

[1] Hess, D.S. and Hess, D.W. (1998) Biliopancreatic Diversion with a Duodenal Switch. Obesity Surgery, 8, 267-282. https://doi.org/10.1381/096089298765554476

[2] Johnston, D., Dachtler, J., Sue-Ling, H.M., et al. (2003) The Magenstrasse and Mil Operation for Morbid Obesity. Obesity Surgery, 13, 10-16. https://doi.org/10.1381/096089203321136520

[3] Gagner, M., Deitel, M., Kalberer, T.L., et al. (2009) The Second International Consensus Summit for Sleeve Gastrectomy. Surgery for Obesity and Related Diseases, $\mathbf{5}$, 476-485. https://doi.org/10.1016/j.soard.2009.06.001

[4] Cottam, D., Qureshi, F.G., Mattar, S.G., et al. (2006) Laparoscopic Sleeve Gastrectomy as an Initial Weight-Loss Procedure for High-Risk Patients with Morbid Obesity. Surgical Endoscopy, 20, 859-863. https://doi.org/10.1007/s00464-005-0134-5

[5] Hamoui, N., Anthone, G.J., Kaufman, H.S., et al. (2006) Sleeve Gastrectomy in the High-Risk Patients. Obesity Surgery, 11, 1445-1449.

https://doi.org/10.1381/096089206778870157

[6] Nocca, D., Krawczkowsky, D., Bomans, B., et al. (2008) A Prospective Multicentric Study of 163 Sleeve Gastrectomies: Results at 1 and 2 Years. Obesity Surgery, 18, 
560-565. https://doi.org/10.1007/s11695-007-9288-7

[7] Soricelli, E., Casella, G., Rizzello, M., et al. (2010) Initial Experience with Laparoscopic Crural Closure in the Management of Hiatal Hernia in Obese Patients Undergoing Sleeve Gastrectomy. Obesity Surgery, 20, 1149-1153.

https://doi.org/10.1007/s11695-009-0056-8

[8] Daes, J., Jimenez, M.E., Said, N., et al. (2012) Laparoscopic Sleeve Gastrectomy; Symptoms of Gastroesophageal Reflux Can Be Reduced by Changes in Surgical Technique. Obesity Surgery, 22, 920-924. https://doi.org/10.1007/s11695-012-0746-5

[9] Chiu, S., Birch, D.W., Shi, X., et al. (2011) Effect of Sleeve Gastrectomy on Gastroesophageal Reflux Disease. A Systemic Review. Surgery for Obesity and Related Diseases, 7, 510-515. https://doi.org/10.1016/j.soard.2010.09.011

[10] Anthone, G.J. (2005) The Duodenal Switch Operation for Morbid Obesity. Surgical Clinics of North America, 85, 819-833. https://doi.org/10.1016/j.suc.2005.03.007

[11] Weiner, R.A., Theodoridou, S. and Weiner, S. (2011) Failure of Laparoscopic Sleeve Gastrectomy: Further Procedure? Obesity Facts, 4, 42-46.

https://doi.org/10.1159/000327343

[12] Korn, O., Stein, H.J., Richter, T.H., et al. (1997) Gastroesophageal Sphincter: Model. Diseases of the Esophagus, 10, 105-109. https://doi.org/10.1093/dote/10.2.105

[13] Korn, O., Csendes, A., Burdiles, P., et al. (2000) Anatomic Dilatation of the Cardia and Competence of the Lower Esophageal Sphincter: A Clinical and Experimental Study. Journal of Gastrointestinal Surgery, 4, 398-406.

https://doi.org/10.1016/S1091-255X(00)80019-0

[14] Braghetto, I., Csendes, A., Korn, O., et al. (2010) Gastroesophageal Reflux Disease after Sleeve Gastrectomy. Surgical Laparoscopy Endoscopy \& Percutaneous Techniques, 20, 148-153. https://doi.org/10.1097/SLE.0b013e3181e354bc

[15] Burgerhart, J.S., Schotborgh, C.A., Schoon, E.J., et al. (2014) Effect of Sleeve Gastrectomy on Gastroesophageal Reflux. Obesity Surgery, 24, 1436-1441.

https://doi.org/10.1007/s11695-014-1222-1

[16] Tai, C.M., Huang, C.K., Lee, Y.C., et al. (2013) Increase in Gastroesophageal Reflux Disease Symptoms and Erosive Esophagitis 1 Year after Laparoscopic Sleeve Hysterectomy among Obese Adults. Surgical Endoscopy, 27, 1260-1265. https://doi.org/10.1007/s00464-012-2593-9

[17] Klaus, A. and Weiss, H. (2008) Is Operative Manometry in Restrictive Bariatric Procedures Necessary? Obesity Surgery, 18, 1323-1329. https://doi.org/10.1007/s11695-007-9399-1

[18] Keidar, A., Appelbaum, L., Schweiger, C., et al. (2010) Dilated Upper Sleeve Can Be Associated with Sever Postoperative Gastro Esophageal Dysmotility and Reflux. Obesity Surgery, 20, 140-147. https://doi.org/10.1007/s11695-009-0032-3

[19] Akkary, E., Duffy, A. and Bell, R. (2008) Deciphering the Sleeve Technique, Indications, Efficacy, and Safety of Sleeve Gastrectomy. Obesity Surgery, 18, 1323-1329. https://doi.org/10.1007/s11695-008-9551-6

[20] Soricelli, E., Iossa, A., Caseella, G., et al. (2012) Sleeve Gastrectomy and Crural Repair in Obese Patients with Gastroesophageal Reflux Disease and or Hiatal Hernia. Surgery for Obesity and Related Diseases, 9, 356-361. https://doi.org/10.1016/j.soard.2012.06.003

[21] Scheepers, A.F., Schoon, E.J. and Nienhuijs, S.W. (2011) Esophageal Carcinoma after Sleeve Gastrectomy. Surgery for Obesity and Related Diseases, 7, e11-e12. 
https://doi.org/10.1016/j.soard.2010.09.019

[22] Sohn, S., Fischer, J. and Booth, M. (2015) Adenocarcinoma of the Gastro-Esophageal Junction after Sleeve Gastrectomy: A Case Report. ANZ Journal of Surgery, 87, E163-E164.

[23] Wright, F.G., Duro, A., Medici, J.R., et al. (2017) Esophageal Adenocarcinoma Five Years after Laparoscopic Sleeve Gastrectomy. A Case Report. International Journal of Surgery Case Reports, 32, 47-50. https://doi.org/10.1016/j.ijscr.2017.01.054 